\title{
Salinity and depth as structuring factors of cryptic divergence in Moina brachiata (Crustacea: Cladocera)
}

\author{
Judit Nédli ${ }^{1,2}$, Luc De Meester ${ }^{3}$, Ágnes Major ${ }^{4} \dagger$, Klaus Schwenk ${ }^{5}$, Ildikó Szivák ${ }^{2}$ \\ and László Forró ${ }^{1}$
}

With 4 figures, 4 tables and 3 supplementary tables

\begin{abstract}
Microcrustacean taxa in temporary waters are important contributors to aquatic biodiversity on the landscape scale even though much of the diversity at the molecular level is still undiscovered. Cladoceran species other than Daphnia are not frequently targeted in molecular investigations. We used nuclear allozyme polymorphisms as well as DNA sequence variation in mitochondrial $16 \mathrm{~S}$ and COI gene regions to reveal patterns of genetic differentiation among populations of a cladoceran species - Moina brachiata - that typically inhabits temporary aquatic habitats. Samples originated from 20 temporary to semi-permanent waterbodies in the Hungarian Great Plain of the Pannonian biogeographic region. We observed strong genetic differentiation in the phylogenetic analyses of the concatenated $16 \mathrm{~S}$ and COI genes, based on which M. brachiata was found to represent a complex of four cryptic lineages (A, B, C and D) with, however, one of these (lineage D) detected based on only one individual. Regarding the nuclear markers, diagnostic alleles of the PGM and MDH enzyme loci in complete linkage disequilibrium were observed separating the 'B' lineage from the rest. In addition, indirect evidence was provided by the AAT locus, where the AAT1 allele was found to be potentially diagnostic for lineage ' $\mathrm{C}$ '. The three phylogenetically defined lineages ('A', 'B', 'C') could be separated from each other along the first canonical axis of a multivariate analysis of occurrence, and this first axis was strongly correlated with depth and salinity of the ponds. There is a strong association between habitat depth and the occurrence of the ' $\mathrm{B}$ ' lineage. Our results indicate that habitat depth and associated ecological characteristics driven by differences in hydroperiod likely are responsible for the present distribution of the lineages.
\end{abstract}

Key words: cryptic species, COI, $16 \mathrm{~S}$, haplotypes, temporary waters, depth, salinity.

\section{Introduction}

Organisms of temporary aquatic habitats require special adaptation strategies to withstand recurrent dry periods. As a consequence, this type of ecosystem is characterised by a specialized and unique fauna and flora and thus is an object of intense research and conservation efforts (Ramsar 2002, Brendonck et al. 2010). Human made changes in hydrologic regimes, levee building for river flood prevention and agricultural expansion have had drastic effects on temporary waters during the last centuries worldwide. In

\footnotetext{
Authors' addresses:

${ }^{1}$ Hungarian Natural History Museum, Department of Zoology, Baross str. 13., Budapest 1088, Hungary

${ }^{2}$ MTA Centre for Ecological Research, Balaton Limnological Institute, 8237 Tihany, Klebelsberg K. str. 3., Hungary

${ }^{3}$ KU Leuven, University of Leuven, Laboratory of Aquatic Ecology, Evolution and Conservation, Charles Deberiotstraat 32 , Leuven 3000, Belgium

${ }^{4}$ Hungarian Natural History Museum, Laboratory of Molecular Taxonomy, Ludovika square 2., Budapest 1083, Hungary

${ }^{5}$ University of Koblenz-Landau, Institute for Environmental Sciences, Molecular Ecology, Fortstrasse 7, Landau 76829, Germany
}

Corresponding author; judit.nedli@gmail.com 
addition, the effects of climate change threaten these aquatic habitats (Hulsmans et al. 2008). The severe decline of biodiversity in freshwater systems during the past decades (Dudgeon et al. 2006, Balian et al. 2008, Naiman 2008, Heino et al. 2009) underscores the importance of research and conservation efforts for these unique temporary habitats.

A number of studies have aimed to unravel biotic and abiotic conditions that locally determine species composition and community structure in temporary waters. Hydroperiod, i.e. the length of the inundated period, is known to structure invertebrate communities (Wellborn et al. 1996, Jenkins et al. 2003, Frisch et al. 2006, Medley \& Havel 2007, Tavernini 2008). In a set of floodplain ponds, habitat depth was found to be a significant local variable influencing species richness and zooplankton community structure (Medley \& Havel 2007) and the effect of water depth on species richness has also been shown for ostracods and cladocerans (Eitam et al. 2004). It has been shown that microcrustacean communities and species richness are influenced by salinity (Boronat et al. 2001, Frisch et al. 2006, Waterkeyn et al. 2008), and the indirect effect of salinity through biological interactions and interactions between certain physical and chemical factors has been emphasised (Williams et al. 1990). Furthermore salinity is known to affect the physiology of cladocerans, to the extent that different osmoregulatory abilities might develop among populations of the same species inhabiting waters of differing salinities (Aladin \& Potts 1995). Salinity has also been shown to influence morphological traits in ostracods (Yin et al. 1999).

Beside local conditions, dispersal of adults or dormant propagules by flooding events, wind, waterfowl, human activity and ecto- and endozoochory (Allen 2007, Green et al. 2008, Waterkeyn et al. 2010, Havel \& Shurin 2004) also affect community composition in temporary aquatic systems. Dispersal rates depend on the availability of source habitats, dispersal mode and the abundance of dispersal vectors.

Biodiversity estimates of the crustacean fauna in aquatic habitats are hindered by incomplete information on delineation of species (Adamowicz \& Purvis 2005). With the recent advances of molecular tools and their broadening application, the number of discoveries of cryptic species in animal taxa increased exponentially in the last decades (Bickford et al. 2007, Pfenninger \& Schwenk 2007), and cryptic lineages are frequently detected among crustaceans as well (Elías-Gutiérrez et al. 2008, Belyaeva \& Taylor 2009, Petrusek et al. 2012). However, despite the recent technical developments, the estimated number of cladoceran species is still likely 2-4 times higher than the currently recognized 620 species (Forró et al. 2008). At the same time, possible forces driving speciation often remain unknown, while knowledge of ecological factors accounting for adaptive processes may provide a useful basis for planning and managing conservation projects.

Most species of the family Moinidae possess a high degree of physiological adaptation to temporary environments, and occur primarily or exclusively in temporary ponds and pools, including saline and alkaline waters (Goulden 1968). Moina macrocopa (Straus, 1820) is a frequently used model species in ecotoxicological research (Gama-Flores et al. 2007, Mangas-Ramírez et al. 2004) and microsatellite markers have been published recently for this species (Tatsuta et al. 2009). Cryptic species have been reported in Moina micrura Kurz, 1875 (Elías-Gutiérrez et al. 2008, Petrusek et al. 2004).

Research on Moina brachiata (Jurine, 1820) (Crustacea: Anomopoda), a widely distributed taxon throughout most of the Old World (Goulden 1968), is relatively scarce. Based on detailed investigation of life history parameters (development, reproduction and growth pattern) in M. brachiata, Maier (1992) concluded that the species has a relatively short egg development period and high egg production rates that are advantageous in unstable environments. The species has a closed brood chamber (Aladin \& Potts 1995) making it capable of regulating the osmolarity of the embryonic environment.

In the present study, Moina brachiata, a common taxon from temporary waters of the Great Plain, was used to study the genetic structure of populations between different regions. We also aimed to investigate to what extent cryptic speciation may have occurred in this taxon. Finally, we also aimed at detecting the role of the abiotic environment in the occurrence of the genetically differentiated M. brachiata populations, since this information might be useful in the selection of habitats for conservation purposes and it might also indicate possible forces driving evolution.

\section{Methods}

\section{Study area and habitats}

The climate of the Hungarian Great Plain is continental, with a relatively long warm season, hot summers and cold winters. The amount of yearly precipitation is variable, but the larger part of it occurs during summer. Typically, the temporary pools in the area fill up twice a year, first after receiving snowmelt run-off in February to March, and later due to early summer 


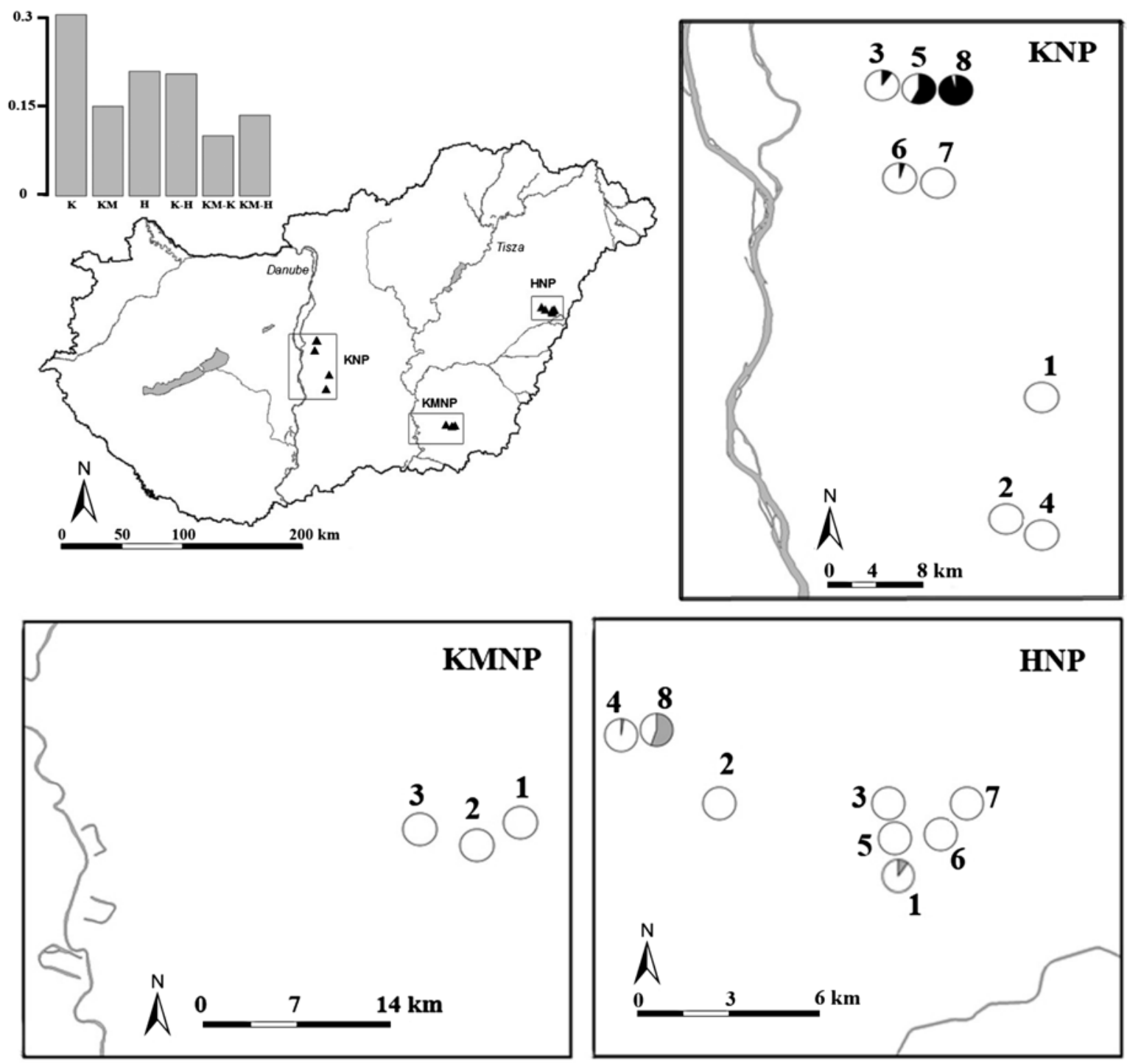

Fig. 1. Allozyme pattern associated with specific clades in the sampled populations on the map of Hungary. Top left barplot shows Fst values within lineage ' $A$ ' in the following order: $\mathrm{K}$ - within KNP, KM - within KMNP, H - within HNP, K-H - among KNP and HNP, KM-K - among KMNP and KNP, KM-H - among KMNP and HNP. Rectangle frame insets show the sampled regions, pie diagrams representing different ponds. Numbers refer to pond numbers (see Table 1). White color in the pie diagrams corresponds to lineage 'A'. Black color in the pie diagrams represents the frequency of the MDH1 allele (i.e. the 'B' lineage). Grey color in the pie diagrams corresponds to the frequency of the AAT1 allele (i.e. the putative ' $\mathrm{C}$ ' lineage). KMNP- Körös- Maros National Park, KNP- Kiskunság National Park, HNP- Hortobágy National Park.

precipitation during June to July. By the end of the hot summer (August) most of the pools dry out and stay dried for the rest of the year. The hydrography of the Great Plain is mainly influenced by the Danube and Tisza rivers. Since the end of the $19^{\text {th }}$ century, significant changes in the hydrological regime have taken place through levee building for flood prevention, building of irrigation channels, artificial river bed alterations and changes in land use, leading to a significant decrease in the number of temporary waterbodies, even though this type of habitat is still found relatively frequently.

Temporary waters for our study were selected in three regions in the Great Plain: in the Kiskunság National Park (KNP), Körös-Maros National Park (KMNP) and Hortobágy National
Park (HNP); see Fig. 1 for their relative position. Hydrological history of the regions is different. Selected sites in the KNP region lie directly on a former floodplain, therefore this region was drastically affected by river regulation. Sites in the HNP are located on an interfluvial plateau along the margin of the former floodplain while the KMNP sites lie on a loess plateau of the interfluve further away from the original floodplain area.

Sampled habitats were temporary or semi-permanent waterbodies (wheeltracks, puddles, pools, flooded depressions in the ground) surrounded by grassland, arable land or pastures. Interesting temporary habitat types in the Kiskunság National Park area are the bomb craters that were formed during the 1950 's when the area was used as a military training ground. 
Due to their depth, most of the bomb craters retain water for an extended period during summer and occasionally they may remain wet throughout the whole year.

\section{Sample collection}

Sampling site selection was accomplished based on prior knowledge of the occurrence of M. brachiata. Sampling was done between $5^{\text {th }}$ April and $23^{\text {rd }}$ June 2006. As 2006 was a very wet year, we aimed to select pools that were not connected to other waterbodies even during the highest water level. Sampling sites were arranged in three clusters corresponding to the Kiskunság (8 sites), Körös-Maros (4 sites) and Hortobágy (8 sites) National Parks (Fig. 1) referred to as 'KNP', 'KMNP' and 'HNP' regions, respectively.

Zooplankton samples were collected using a plankton net of $85 \mu \mathrm{m}$ mesh size. Samples were placed into a white plastic tray and organisms were sorted in the field using magnifying glasses. Animals for cellulose acetate gel electrophoresis were placed into cryotubes (around 15 specimens per tube) and flash-frozen in liquid nitrogen for transport to the laboratory. We aimed to collect 60 individuals per population wherever this was possible. Additional individuals were preserved in $96 \%$ ethanol and stored at $5{ }^{\circ} \mathrm{C}$ until use for DNA extraction. Egg-bearing parthenogenetic $M$. brachiata females were selected under the microscope in the laboratory directly before molecular analyses. Identification of the animals followed Goulden (1968). Four $M$. macrocopa individuals were also selected and sequenced to be used as the outgroup in the phylogenetic analyses.

Environmental variables were recorded for each pool (Table 1). We measured salinity and pH (WTW Multiline P3) and the geographical coordinates of the pools. Maximum water depth and the distance between the sampled pool and the near- est waterbody were measured with a measuring tape. Surface area at the time of the sampling was estimated based on direct measurements by tape measure for pools not exceeding $40 \mathrm{~m}$ in length, while surface area of pools over this size was estimated by eye.

\section{mtDNA variation}

DNA extraction procedures were conducted based on the $\mathrm{H} 3$ method (Schwenk et al. 1998). We used $100 \mu \mathrm{H} 3$ buffer and $20 \mu \mathrm{l}$ proteinase $\mathrm{K}$ (Fermentas, $18 \mathrm{mg} / \mathrm{ml}$ ) per individual in the reactions. In the case of parallel analyses of allozyme and mitochondrial DNA variation, we used $5 \mu 1$ sterile ultrapure water to emacerate each individual and placed $1.5 \mu 1$ of this homogenate into $20 \mu \mathrm{l} \mathrm{H} 3$ buffer with $6 \mu \mathrm{l}$ proteinase $\mathrm{K}$. The rest of the homogenate was diluted with $5 \mu 1$ sterile ultrapure water to be used for cellulose acetate gel electrophoresis.

The universal primer LCO1490 (5'- GGTCAACAAATCATAAAGATA -3') (Folmer et al. 1994) and COI-H (5'TCAGGGTGACCAAAAAATCA -3') (Machordom et al. 2003 ) were used to amplify an approximately $660 \mathrm{bp}$ region of the mitochondrial cytochrome oxidase subunit I. For the $16 \mathrm{~S}$ region we used S1 (5'-CGG CCG CCT GTT TAT CAA AAA CAT $\left.-3^{\prime}\right)$ and S2 (5' - GGAGCT CCG GTT TGA ACT CAG ATC -3') (Schwenk et al. 1998).

PCR amplification of the $16 \mathrm{~S}$ region was conducted in $25 \mu \mathrm{l}$ volumes containing $5 \mu \mathrm{l}$ homogenate, $1 \times$ reaction buffer $+\left(\mathrm{NH}_{4}\right)_{2} \mathrm{SO}_{4}$ (Fermentas), $2.5 \mathrm{mM} \mathrm{MgCl}_{2}, 200 \mu \mathrm{M}$ of each dNTP, $0.2 \mu \mathrm{M}$ of the primers and $0.5 \mathrm{U} / \mu 1$ Taq polymerase (Fermentas). Thermal cycle settings for the $16 \mathrm{~S}$ region were $94{ }^{\circ} \mathrm{C}$ for $5 \mathrm{~min}$ followed by 40 cycles of $93{ }^{\circ} \mathrm{C}$ for $45 \mathrm{~s}, 50{ }^{\circ} \mathrm{C}$ for $1 \mathrm{~min}, 72^{\circ} \mathrm{C}$ for $2 \mathrm{~min}$ and an additional elongation step at $72{ }^{\circ} \mathrm{C}$ for $2 \mathrm{~min}$.

Table 1. Summary of the environmental characteristics of the sampling sites and the number of individuals (N) per population used in the allozyme analyses. Pop: population identifier, EOVX and EOVY: geographical coordinates (Hungarian uniform national projection), Sal: salinity $(\mathrm{g} / \mathrm{l})$, depth $(\mathrm{cm})$, near: distance to nearest pool $(\mathrm{m})$, surface: surface area of the pond $\left(\mathrm{m}^{2}\right)$ at the time of sampling. Population KMNP4 could not be analysed for enzyme polymorphism.

\begin{tabular}{|c|c|c|c|c|c|c|c|c|}
\hline Pop & EOVX & EOVY & $\mathbf{N}$ & Sal & pH & depth & near & surface \\
\hline HNP1 & 220965 & 851346 & 29 & 0.5 & 8.4 & 10 & 2 & 120 \\
\hline HNP2 & 223394 & 845552 & 42 & 0 & 7.9 & 20 & 0.8 & 20 \\
\hline HNP3 & 222512 & 851228 & 39 & 0.3 & 8.7 & 10 & 16 & 4.5 \\
\hline HNP4 & 225404 & 842505 & 41 & 0.2 & 8.4 & 30 & 1 & 100 \\
\hline HNP5 & 221956 & 851306 & 23 & 1.1 & 8.6 & 30 & 26 & 2 \\
\hline HNP6 & 222557 & 852800 & 30 & 1.1 & 8.2 & 10 & 1 & 2.5 \\
\hline HNP7 & 223166 & 853424 & 37 & 3.2 & 9.0 & 10 & 1 & 0.45 \\
\hline HNP8 & 225455 & 842677 & 36 & 0 & 7.4 & 45 & 6 & 50 \\
\hline KNP1 & 169491 & 666722 & 55 & 0.1 & 7.8 & 30 & 7 & 150 \\
\hline KNP2 & 157646 & 664143 & 41 & 0 & 7.8 & 30 & 2 & 10.5 \\
\hline KNP3 & 197539 & 656022 & 31 & 2.5 & 8.8 & 50 & 4 & 300 \\
\hline KNP4 & 157432 & 664305 & 47 & 0.1 & 8.5 & 15 & 0.5 & 6 \\
\hline KNP5 & 197444 & 656530 & 33 & 2.6 & 9.6 & 120 & 10 & 113 \\
\hline KNP6 & 189725 & 654948 & 42 & 5.9 & 9.2 & 10 & 2 & 1 \\
\hline KNP7 & 189740 & 655000 & 32 & 1.6 & 8.6 & 10 & 2 & 0.8 \\
\hline KNP8 & 197380 & 656804 & 44 & 3.2 & 9.3 & 130 & 7 & 133 \\
\hline KMNP1 & 127248 & 770718 & 40 & 0.5 & 8.6 & 30 & 2 & 68000 \\
\hline KMNP2 & 126457 & 768297 & 16 & 0 & 8.8 & 15 & 1 & 18 \\
\hline KMNP3 & 127942 & 763462 & 40 & 0 & 8.6 & 25 & 25 & 300 \\
\hline KMNP4 & 126427 & 768660 & - & 0.4 & 8.3 & 30 & 25 & 40 \\
\hline
\end{tabular}


PCR amplifications of the COI region were conducted in $25 \mu \mathrm{l}$ volumes containing $10 \mu \mathrm{l}$ homogenate, $1 \times$ reaction buffer $+\left(\mathrm{NH}_{4}\right)_{2} \mathrm{SO}_{4}$ (Fermentas), $2 \mathrm{mM} \mathrm{MgCl}{ }_{2}, 250 \mu \mathrm{M}$ of each $\mathrm{dNTP}, 0.35 \mu \mathrm{M}$ of the primers and $0.5 \mathrm{U} / \mu \mathrm{l}$ Taq polymerase (Fermentas). For the cytochrome oxidase I region we used $94{ }^{\circ} \mathrm{C}$ for $1 \mathrm{~min}$ followed by 40 cycles of $94^{\circ} \mathrm{C}$ for $1 \mathrm{~min}, 40^{\circ} \mathrm{C}$ for $1 \mathrm{~min} 30 \mathrm{~s}, 72^{\circ} \mathrm{C}$ for $1 \mathrm{~min} 30 \mathrm{~s}$ and the final elongation at $72{ }^{\circ} \mathrm{C}$ for $6 \mathrm{~min}$.

After cleaning of the PCR products (High Pure PCR Product Purification Kit, Roche Diagnostics) sequencing followed on an ABI 3130 Genetic Analyser according to the producers' instructions. The same primer pairs as for the PCR amplifications were used to sequence the regions from both directions. Multiple sequence alignments were carried out using BioEdit version 7.0.5.3 (Hall 1999) and checked by eye. Descriptive statistics for the obtained sequences were calculated with DnaSP v5 (Librado \& Rozas 2009).

Every detected concatenated $16 \mathrm{~S}+\mathrm{COI}$ M. brachiata haplotype and two M. macrocopa haplotypes (Mmac1 and Mmac2) were used for phylogenetic analysis with the outgroup Polyphemus pediculus (Linné, 1761) AY075048 for 16 S and AY075066 for COI (Cristescu \& Hebert 2002). Model selection and phylogenetic analysis by maximum likelihood was done in TREEFINDER (Jobb 2008). Model selection by Akaike information criterion corrected for finite sample sizes (AICc) resulted in the transversion model (TVM) (Posada 2003) for the $16 \mathrm{~S}$ (475 bp) gene while the $\mathrm{J} 2$ model (Jobb 2008) was selected for the COI (605 bp) region. For both genes the discrete Gamma heterogeneity model with four rate categories was applied. Nonparametric bootstrap support to assess internal branch support was calculated by 1000 replicates, and the $50 \%$ majority-rule consensus tree was built under the partitioned model. Branch support through posterior clade probability for the same partitioned dataset was assessed in MrBayes 3 (Huelsenbeck \& Ronquist 2001, Ronquist \& Huelsenbeck 2003). Since TVM and J2 are not implemented in this software, calculations were done under the GTR $+\mathrm{G}$ model with 4 rate categories for $16 \mathrm{~S}$ and the $\mathrm{HKY}+\mathrm{G}$ model with 4 rate categories for COI. Two independent analyses were started from random starting trees and ran for 1001000 generations. The Markov chains were sampled each 100 generations, and final statistics were calculated after discarding the first 2500 trees as burn-in.

To illustrate the level of diversification within the Moina genus and to make a comparison to the well-known Daphnia longispina group, an additional phylogenetic reconstruction was carried out for the COI gene $(604 \mathrm{bp})$ only. This second analysis contained one $M$. brachiata haplotype from each putative lineage detected in the prior analysis of the concatenated dataset. To compare divergence within M. brachiata to divergence within other Moina species we also included one M. macrocopa individual collected in Hungary and sequenced for the present study. The other M. macrocopa (GenBank accession number EU702249), three lineages of M. micrura from Mexico (GenBank accession numbers: EU702207, EU702239, EU702244) and one Ceriodaphnia dubia Richard, 1894 haplotype (GenBank accession number EU702080) used as outgroup were sequenced by Elías-Gutiérrez et al. (2008). Daphnia longispina (EF375862) and Daphnia lacustris (EF375863) were published by Petrusek et al. (2008). In addition, Daphnia dentifera (FJ427488) (Adamowicz et al. 2009), Daphnia mendotae (GQ475272) (Briski et al. 2011), Daphnia galeata (JF821192) and Daphnia cucullata (JF821190) (unpublished sequences downloaded from GenBank) were included in the analysis.

Model selection and phylogenetic reconstruction by maximum likelihood under the GTR+GI model with four rate categories was carried out in TREEFINDER (Jobb 2008). Nonparametric bootstrap analysis with 1000 replicates was done to assess internal branch support. Bayesian inference by two independent analyses from random starting trees was calculated in MrBayes (Huelsenbeck \& Ronquist 2001, Ronquist \& Huelsenbeck 2003) under the same model. Generation, sampling and burn-in settings for this analysis were set as for the concatenated dataset. Branch support was assessed through posterior clade probabilities.

Pairwise sequence divergence estimates of the COI gene under the $\mathrm{K} 2 \mathrm{p}$ model with uniform rates among sites were calculated in MEGA 5.01 (Tamura et al. 2011) for the same dataset.

A minimum spanning network at $99 \%$ connection limit was generated with TCS 1.21 (Clement et al. 2000) based on the statistical parsimony cladogram estimation method (Templeton et al. 1992). The analysis was carried out for joined $16 \mathrm{~S}$ and COI regions. The network therefore includes only the animals (53) for which sequencing was successful for both genes.

\section{Cellulose acetate gel electrophoresis}

Cellulose acetate gel electrophoresis was used to reveal enzymatic variability within $M$. brachiata at five loci: supernatant aspartate amino transferase (sAAT; EC 2.6.1.1), glucose6-phosphate isomerase (GPI; EC 5.3.1.9), supernatant malate dehydrogenase (sMDH; EC 1.1.1.37), mannose-6-phosphate isomerase (MPI; EC 5.3.1.8) and phosphoglucomutase (PGM; EC 5.4.4.2). Individuals were emacerated in $5 \mu \mathrm{l}$ sterile ultrapure water before application to the gel (Helena Super Z-12 Applicator kit, Helena Laboratories, Beaumont, Texas). Gel electrophoresis was conducted at $270 \mathrm{~V}$ (ZipZone Chamber, Helena Laboratories). Individuals of a parthenogenetically reared Daphnia pulex Leydig, 1860 clone were used as markers in each run in the ninth position on the gel. The buffer system used for running PGM (15 min runtime), MPI (10 min) and PGI (15 min) was $\mathrm{pH} 8.7$ tris-citrate $(39 \mathrm{mM}$ Tris, $0.001 \mathrm{M}$ EDTA, $2.5 \mathrm{mM}$ citric acid). To run $\mathrm{MDH}$ (15 min) $\mathrm{pH} 7.3$ tris-citrate buffer ( $36.45 \mathrm{mM}$ Tris, $14.3 \mathrm{mM}$ citric acid) and to run AAT (25 $\mathrm{min}) \mathrm{LiOH}-$ boric acid buffer $(11.89 \mathrm{~g}$ boric acid and $1.175 \mathrm{~g}$ $\mathrm{LiOH}$ for $1000 \mathrm{ml}$ buffer) was used. Staining procedures were carried out following the protocols described by Hebert \& Beaton (1989). Migration lengths of the different alleles were measured from the application position.

\section{Data analysis on population genetic structure and environmental factors}

Standard population genetic characteristics (allele frequencies, heterozygosity) were quantified from the allozyme data using the software TFPGA (Miller 1997). In addition, we carried out hierarchical Wright's F statistics analyses on the dataset. Animals with missing alleles were excluded from the descriptive and hierarchical population genetic analyses. Wright's F statistics was calculated based on the method of Weir \& Cockerham (1984).

Links between genetic divergence of M. brachiata populations and abiotic characteristics were addressed by Constrained Analysis of Principal Coordinates (CAP) (Legendre \& Ander- 
son 1999). The distance matrix of the response variable for the analysis was generated with TFPGA (Miller 1997), calculating pairwise Nei's unbiased genetic distances (Nei 1978) between all population pairs that contained at least 14 specimens. In populations where multiple lineages co-occurred, we either removed individuals from lineages that occurred at low frequency (in practice AAT1 or PGM1 allele bearing individuals), or, if these lineages occurred in 14 or more individuals, we kept them separately and included them as separate populations in the analysis. Environmental data were $\log _{10}(\mathrm{x}+1)$ transformed prior to the analysis to have approximate normally distributed random errors (Jongman et al. 1995). pH was omitted from further analysis since it displayed significant correlation with salinity (Spearman's $\mathrm{r}_{\mathrm{pH} \text {-salinity }}=0.717, p<0.01$ ). The environmental variables were first screened via forward selection procedure with Monte Carlo randomization tests (4999 runs, $\alpha=0.1$ ) within CAP to determine a reduced set of significant variables for the final model. Furthermore AIC values were calculated for each step within the procedure to select the best fitting model to the observed genetic structure. We conducted variance partitioning procedure within CAP to determine the relative influences of selected environmental variables. Additional Monte Carlo permutation tests (4999 runs, $\alpha=0.1$ ) were performed to determine the significance of individual environmental variables and canonical axes. To clarify the meaning of canonical axes we calculated Pearson correlations between the axes and significant environmental variables. Finally, we performed additional variance analyses (Kruskal-Wallis tests) to quantify the differences between the phylogenetically defined lineages ('A', 'B', 'C') along the canonical axes. Thus we used object scores projected on the canonical axes as explanatory variables and previously defined lineages ('A', 'B', 'C') as grouping variables. The statistical analyses were performed with software R ver. 2.14.0 (R Development Core team 2011) using the package 'vegan'.

\section{Results}

\section{Deep lineage divergence and connection to environmental factors}

Sequences of COI or $16 \mathrm{~S}$ or both were successfully acquired from $74 \mathrm{M}$. brachiata individuals altogether. A list of GenBank accession numbers obtained in this study can be found in Supplementary Table 1, along with allozyme data for individuals for which nuclear and mitochondrial markers were investigated from the same individual. For COI we obtained $627 \mathrm{bp}$ fragments without alignment gaps or missing data for $57 \mathrm{M}$. brachiata specimens, representing 17 haplotypes. 109 variable sites were detected, 102 of them being parsimony informative. For the $16 \mathrm{~S}$ region $516 \mathrm{bp}$ long fragments were acquired from $70 \mathrm{M}$. brachiata specimens, with one insertion-deletion site segregating for two indel haplotypes. Out of 40 variable sites 31 proved to be informative for parsimony.

Maximum likelihood (ML: $-\operatorname{lnL}=3525.78$ ) and Bayesian analysis (Bayesian best likelihood: - $\operatorname{lnL}$
$=3555.52)$ of the concatenated $16 \mathrm{~S}$ and $\mathrm{COI}$ genes resulted in the same topology (Figure 2), confirming the existence of four different clades ('A', 'B', ' $\mathrm{C}$ ' and 'D') within the morphospecies M. brachiata.

Nuclear support for the deep lineage divergence comes from the allozyme electrophoresis. Detected allele frequencies and heterozygosities for each locus are listed in Supplementary Table 2 along with migration lengths of the different alleles observed under the applied electrophoretic conditions. Two alleles of different mobility (assigned as ' 1 ' and '2') were detectable at the MDH locus, while there were four alleles present at the PGM locus. The MDH1 and the PGM1 alleles occurred only in homozygous form and the multilocus genotypes of these two loci were in complete linkage disequilibrium $(\mathrm{D}=1)$ for the entire dataset.

Allozyme and mtDNA investigations from the same individuals confirmed that the PGM1 and MDH1 alleles are diagnostic for the ' $\mathrm{B}$ ' clade (Supplementary Table 1. individuals: $35,36,37,38,41,43,44)$.

The AAT1 allele was found in three populations (Supplementary Table 2 and Fig. 1), either as homozygotes or as heterozygotes combined with only one other allele (AAT2). AAT1 occurred at high frequency (0.556) only in the HNP8 population, where the mitochondrial ' $\mathrm{C}$ ' lineage was also detected. Direct evidence (mtDNA investigation and allozyme analysis of the same individual) for an association between the AAT1 allele and the ' $C$ ' lineage was not provided, but putatively they are connected. Nuclear support for the separation of the ' $\mathrm{D}$ ' clade was not found based on the investigated allozyme markers.

The model including the salinity and the depth of ponds could significantly (if $\alpha=0.1$ ) explain the variability in the observed genetic structure and was best fitted to the genetic structure based on the forward selection procedure within CAP analysis (Table 2).

Table 2. Results of forward selection procedure with Monte Carlo randomization tests (4999 runs, $\alpha=0.1$ ). Best fitting model to the observed genetic structure in bold. Abbrev.: sal: salinity $(\mathrm{g} / \mathrm{l})$, depth $(\mathrm{cm})$, near: distance to nearest pool $(\mathrm{m})$, surface: surface area of the pond $\left(\mathrm{m}^{2}\right)$.

\begin{tabular}{lccc}
\hline & F-value & p-value & AIC \\
\hline null model without env. variables & & & 23.80 \\
sal & 5.253 & 0.018 & 20.68 \\
sal+depth & 2.957 & 0.081 & 19.47 \\
sal+depth+near & 0.615 & 0.499 & 20.72 \\
sal+depth+surface & 0.066 & 0.966 & 21.39 \\
sal+depth+surface+near & 2.172 & 0.099 & 22.66 \\
\hline
\end{tabular}




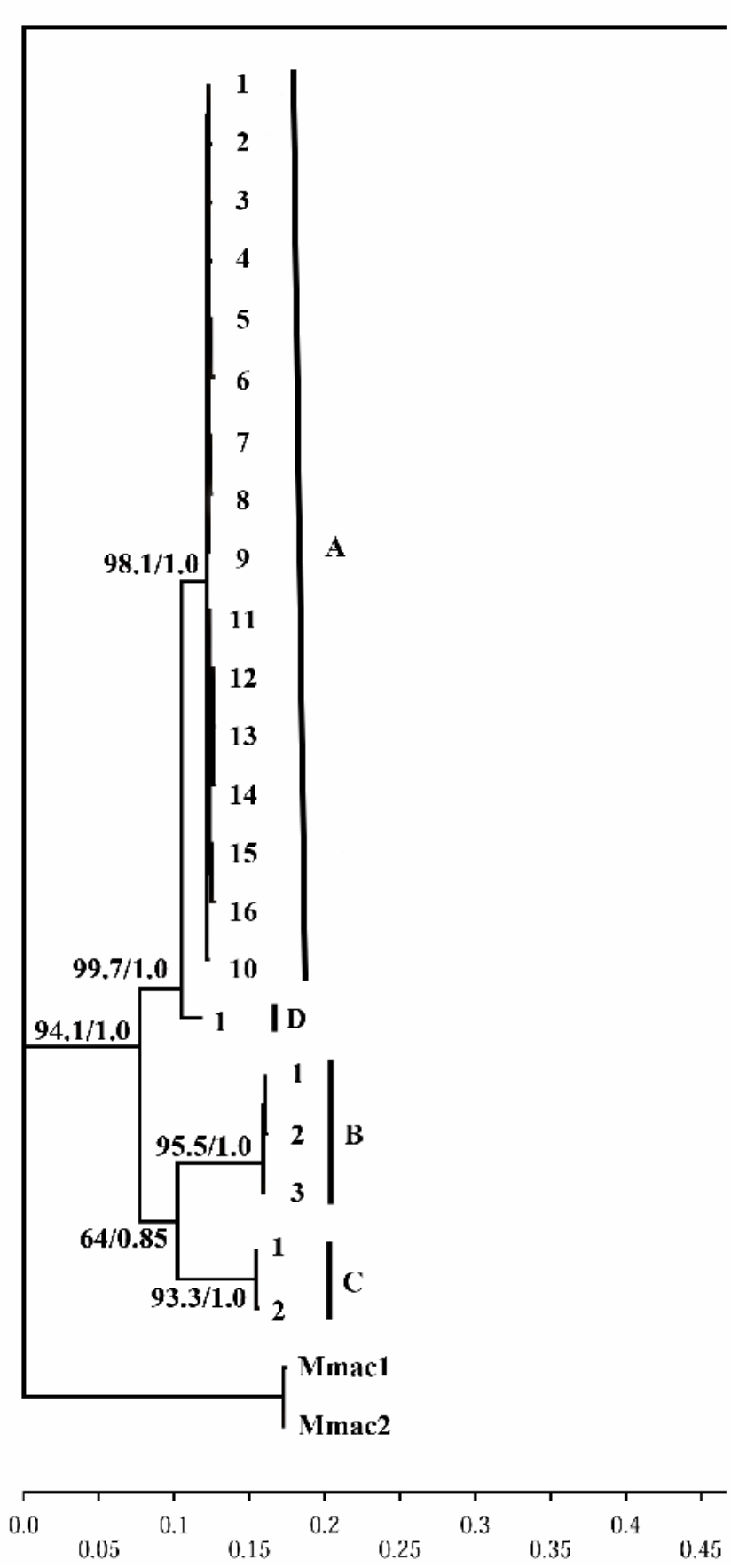

\section{Polyphemus}

Fig. 2. $50 \%$ majority rule consensus tree for the concatenated $16 \mathrm{~S}$ and COI regions (1080bp), for $22 \mathrm{M}$. brachiata haplotypes, two M. macrocopa (Mmac) haplotypes and Polyphemus pediculus as outgroup. M. brachiata haplotypes are encoded by the same numbers as on Fig. 4 and Supplementary Table 1 . The tree has been inferred by maximum likelihood under the TVM $+\mathrm{G}$ substitution model for $16 \mathrm{~S}$ and the $\mathrm{J} 2+\mathrm{G}$ model for COI. Clade support was calculated through 1000 bootstrap replicates. Bayesian inference was calculated under the $\mathrm{GTR}+\mathrm{G}$ model for $16 \mathrm{~S}$ and the $\mathrm{HKY}+\mathrm{G}$ model for COI. Bootstrap support / Bayesian posterior probability is indicated over the main branches. Scale bar shows distances in substitution per site.

These two variables together explained $34.06 \%$ of the total variance in genetic structure. The relative contribution to the total variability in genetic structure was higher for salinity $(15.53 \%)$ than for depth $(11.47 \%)$ based on variance partitioning procedure, and their effects were significant (if $\alpha=0.1$ ) based on Monte Carlo permutation test (4999 runs) (Table 3). The first canonical axis (CAP1) explained $33.9 \%$ of the total variability in the dataset, while this value was negligible in the case of the second canonical axis (CAP2)
(Table 3). Monte Carlo permutation tests (4999 runs) indicated that the first and all canonical axes were significant (if $\alpha=0.1$ ) with respect to the set of variables used (Table 3). The selected environmental variables positively and significantly correlated with CAP1 (salinity: $\mathrm{r}=0.51, p=0.021$; depth: $\mathrm{r}=0.46, p=0.039$ ), but did not with CAP2 (salinity: $\mathrm{r}=-0.1, p=0.683$; depth: $\mathrm{r}=0.11, p=0.633$ ). Besides, the Kruskal-Wallis test on the objects score of CAP1 showed significant differences ( $\left.\mathrm{df}=2, \chi^{2}=7.33, p=0.026\right)$ among the 
phylogenetically defined lineages ('A', 'B', 'C'), but this was not the case for the object scores on CAP2 (df $=2, \chi^{2}=1.70, p=0.43$ ). Summarizing our findings, the three phylogenetically defined lineages ('A', 'B', ' $C$ ') were clearly separated from each other along the first canonical axes characterized by strong gradients in depth and salinity of the ponds.

\section{M. brachiata divergence in comparison to divergence in the Daphnia longispina group}

Genealogy of the COI gene (Fig. 3; ML: - lnL $=3886.29$; Bayesian best likelihood: $-\operatorname{lnL}=3888.68$ ) illustrates the level of divergence within $M$. brachiata compared to other taxa of the Moina genus, and to the well-known Daphnia longispina species group. The pairwise sequence divergence of COI (Supplementary Table 3) within M. brachiata ranged from 0.038 (between ' $A$ ' and ' $D$ ') to 0.132 (between ' $A$ ' and ' $C$ ') with an average of 0.105 . Divergence detected between the Mexican and the Hungarian Moina macrocopa was 0.128. Divergence between different Moina micrura lineages from Mexico ranged from 0.115 to 0.124 (average 0.119). Mean sequence divergence between the Moina brachiata and the Moina macrocopa groups was 0.175 (minimum value: 0.163 , maximum value: 0.195 ) while between M. brachiata and M. micrura it ranged from 0.154 to 0.198 with an average of 0.170 . The lowest interspecific sequence divergence value

Table 3. The relative contributions of the canonical axes (CAP1, CAP2 and all axes) and the selected environmental variables to the observed variation in occurrence of cryptic taxa and the results of Monte Carlo permutation test (4999 runs, $\alpha=0.1)$ in the CAP analysis.

\begin{tabular}{lccc}
\hline & \% var. example & \multicolumn{2}{c}{ Monte Carlo permut. test } \\
\cline { 3 - 4 } & & F-value & $\boldsymbol{p}$-value \\
\hline Canonical axes & 33.86 & 8.729 & 0.006 \\
CAP1 & 0.20 & 0.052 & 0.984 \\
CAP2 & 34.06 & 4.391 & 0.015 \\
all axes & & & \\
Selected variables & 15.53 & 4.004 & 0.042 \\
salinity & 11.47 & 2.957 & 0.081 \\
depth & 7.06 & & \\
salinity+depth (shared effect) & & & \\
\hline
\end{tabular}

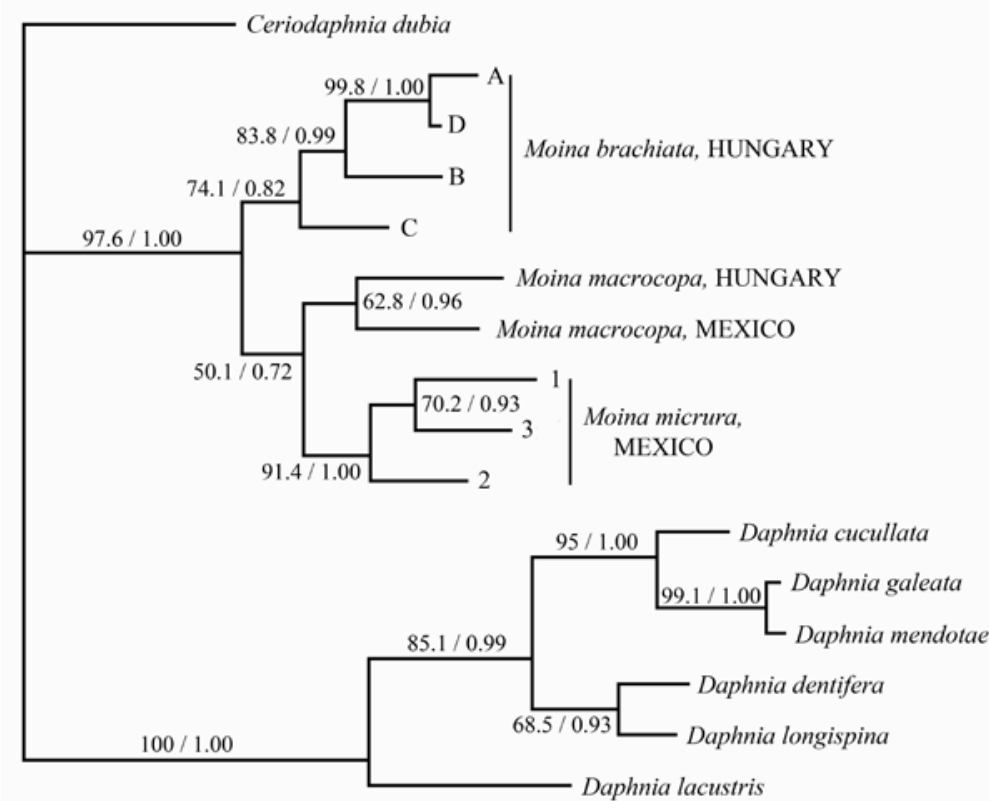

0. 0.05 0.

0.15

0

21

0.3

0.4

0.5
Fig. 3. $50 \%$ majority rule consensus tree of COI (604 bp) for certain Moina and Daphnia haplotypes with Ceriodaphnia dubia as outgroup. The tree was inferred by maximum likelihood under the GTR+GI substitution model: branch support was assessed by 1000 bootstrap replicates. Bootstrap support / Bayesian posterior probability is indicated on the branches. Scale bar shows distances in substitution per site. 
(0.142) within the Moina genus was detected between M. macrocopa and M. micrura while the maximum value between these species was 0.166 and the mean 0.161 .

Within the Daphnia cucullata - galeata - mendotae complex of the longispina-group sequence divergences ranged from 0.022 (between Daphnia galeata and Daphnia mendotae) to 0.116 (between D. cucullata and D. galeata) with an average value of 0.084 . Sequence divergence between Daphnia dentifera and Daphnia longispina was 0.088. Sequence divergence estimates between the D. cucullata - galeatamendotae complex and the D. dentifera - longispina group were $0.144,0.184,0.165$ (minimum, maximum, mean).

\section{Genetic structure in space and genetic variation within the most common lineage}

Haplotype network analysis of the pooled COI $+16 \mathrm{~S}$ regions for 53 animals revealed 22 different haplo-

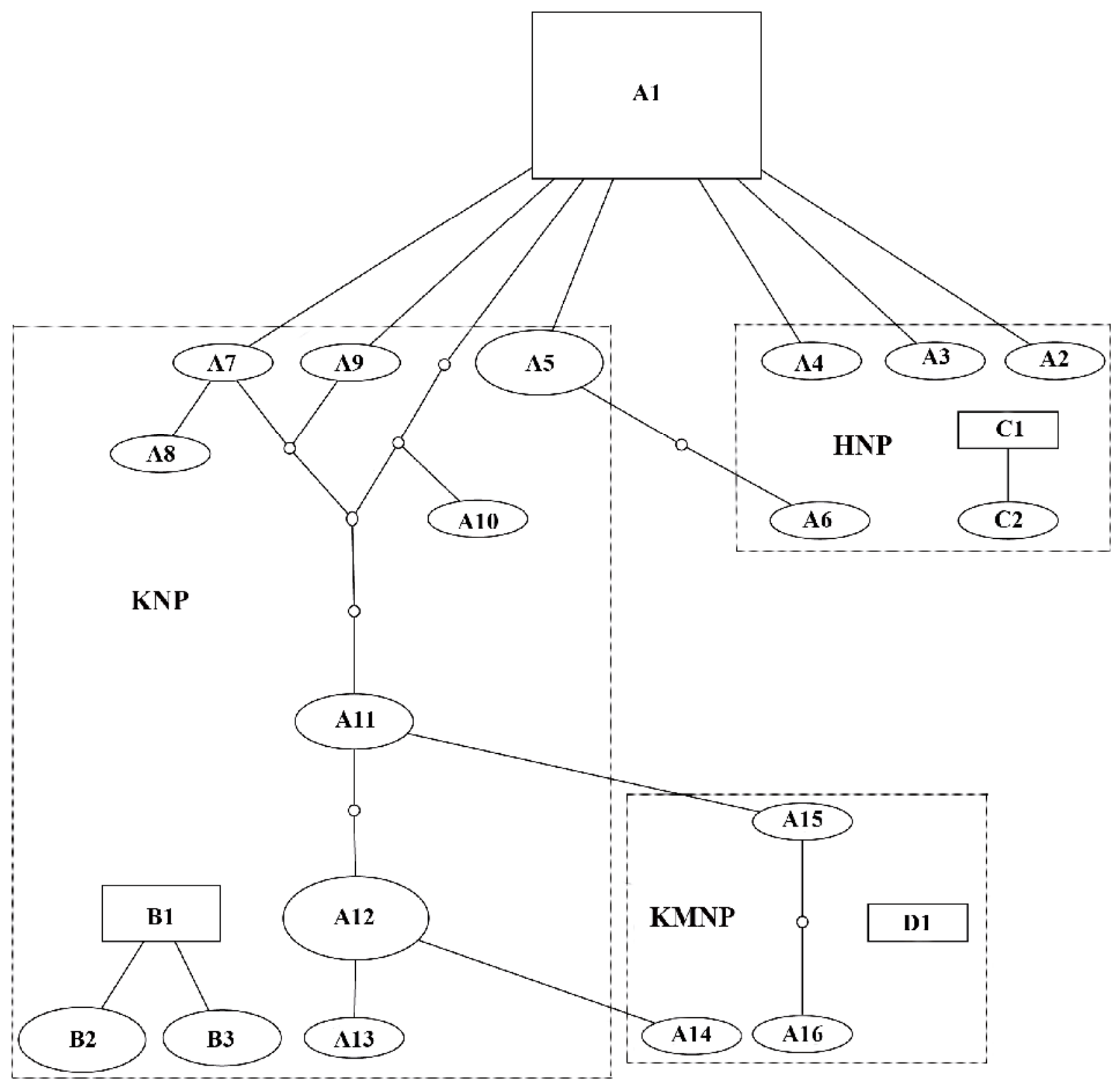

Fig. 4. Minimum spanning network of the joined COI and $16 \mathrm{~S}$ regions for $53 \mathrm{M}$. brachiata specimens. Size of the geometric figures in the network is proportional to the number of times the haplotype was observed. Haplotype A1 occurred in every region; haplotypes in hatched line rectangle frames occurred only in the marked region (KNP, KMNP or HNP). Letters (A, B, C and D) in the haplotype identifiers correspond to the different lineages while numbers identify the individual haplotypes. Haplotype identifiers are the same as in Supplementary Table 1 and on Fig. 2. 
types, which clustered into four separated networks ('A', 'B', 'C' and 'D', Fig. 4). The clades revealed by the phylogenetic analyses based on the pooled $16 \mathrm{~S}$ and COI correspond to the four different network clusters in the haplotype network analysis (Figs 2 and 4). The most widespread and common haplotype 'A1' showed the highest number of connections of the whole dataset. Furthermore this is the only haplotype that occurred in all of the three investigated regions. Other haplotypes in the haplotype network cluster ' $A$ ' were found only in one of the regions (Fig. 4). Haplotype network cluster ' $\mathrm{B}$ ' includes three haplotypes ('B1', 'B2' and 'B3') that were found only in the KNP region. Haplotype network cluster ' $\mathrm{C}$ ' consists of two haplotypes (' $\mathrm{C} 1$ ' and ' $\mathrm{C} 2$ ') occurring only in the HNP region. Haplotype network ' $\mathrm{D}$ ' was represented by one individual found in the KMNP.

Figure 1 illustrates the distribution of the MDH1 and AAT1 alleles in the three national parks. Individuals with the MDH1 allele were observed only in the KNP, while the occurrence of the AAT1 allele was restricted to HNP. The allele frequency of the MDH1 allele was high in two bomb crater habitats (KNP5 and KNP8), while it also occurred in a pool on a pasture (KNP3) and in a wheeltrack (KNP6) at low frequency (Supplementary Table 2 and Fig. 1). The AAT1 allele occurred at high frequency in the HNP8 habitat while in the HNP1 and HNP4 populations its frequency was low (0.103 and 0.024 , respectively).

In the enzyme polymorphism analysis of individuals of the 'A' clade only (and with exclusion of populations KNP8 and HNP8 because of the small number of individuals), the MDH and AAT loci are monomorphic and the resulting dataset contains data

Table 4. Wright's F-statistics for the studied populations of lineage 'A'. Fit: overall inbreeding coefficient of an individual relative to the total set of individuals studied, Fst: coancestry coefficient for individual populations relative to the total set of individuals studied, Frt: coancestry coefficient for regions (KNP, KMNP, HNP) relative to the total set of individuals studied, Fis: inbreeding coefficient for individuals within populations. S.D.: standard deviation, C.I.: upper and lower bounds of $95 \%$ confidence intervals after bootstrapping (5000 replicates) over loci.

\begin{tabular}{lcccc}
\hline Locus & Fit & Fst & Frt & Fis \\
\hline PGI & 0.17 & 0.23 & 0.14 & -0.09 \\
MPI & 0.34 & 0.31 & 0.01 & 0.04 \\
PGM & 0.23 & 0.22 & 0.07 & 0.01 \\
Overall & 0.24 & 0.25 & 0.08 & -0.02 \\
average & 0.24 & 0.25 & 0.08 & -0.02 \\
S.D. & 0.05 & 0.03 & 0.04 & 0.04 \\
C.I. & $0.34 ; 0.17$ & $0.31 ; 0.22$ & $0.14 ; 0.01$ & $0.04 ;-0.09$ \\
\hline
\end{tabular}

for three loci (PGI, MPI and PGM) on 588 individuals from 17 temporary waterbodies. Wright's F-statistics calculated for this dataset are listed in Table 4. Genetic differentiation was high (overall Fst 0.25 ) between populations but negligible (overall Frt 0.08 ) between the three regions (KNP, HNP and KMNP). Average Fst values within the three regions and among pairwise region comparisons (KNP - HNP, KNP - KMNP, KMNP - HNP) are plotted in Fig. 1.

\section{Discussion}

\section{Cryptic taxa}

Based on the results presented in this study, we can conclude that M. brachiata is a complex of at least four cryptic lineages (clades 'A', 'B', 'C' and 'D'). Whether these lineages represent different biological species is not unambiguous for each lineage, but a number of arguments support the separation at the species level for most of the lineages. It is true that the sequence divergence under the K $2 \mathrm{p}$ model among the detected cryptic lineages of M. brachiata do not reach the molecular threshold of species delimitation in crustaceans (Lefébure et al. 2006) but sequence divergence between Daphnia cucullata and Daphnia galeata in our investigations equaled that between Moina brachiata ' $\mathrm{C}$ ' and ' $\mathrm{B}$ ', while divergence between the M. brachiata ' $\mathrm{A}$ ' and ' $\mathrm{B}$ ', ' $\mathrm{A}$ ' and ' $\mathrm{C}$ ', ' $\mathrm{C}$ ' and ' $D$ ' taxon-pairs was even higher than this value. The species status of lineage ' $\mathrm{B}$ ' is strongly supported by the separation in complete linkage disequilibrium for two nuclear loci (MDH and PGM), proving the existence of reproductive isolation between lineages ' $A$ ' and ' $B$ ' that were found to coexist in some habitats. The association of the nuclear and mitochondrial markers was clear, as we used the same individuals for assessing enzyme polymorphisms and sequencing. Elías-Gutiérrez et al. (2008) considered the three Moina micrura lineages detected by them as different species and the divergence between the M. brachiata lineages found in Hungary is comparable to that between M. micrura species ' 1 ', ' 2 ' and ' 3 ' in Mexico.

Direct evidence through DNA sequence and allozyme electrophoresis data on the same individuals was not provided for the separation of the ' $\mathrm{C}$ ' lineage, but the detected pattern (i.e. mitochondrial lineage ' $\mathrm{C}$ ' and the AAT1 allele at a high frequency found in the same pool and only in that pool, HNP8) is unlikely to be caused by chance. The fact that the AAT1 allele occurred both in homozygous and heterozygous form raises the possibility of hybridisation between the dif- 
ferent M. brachiata lineages, but elucidating this pattern was beyond the scope of the present study. Our study was restricted to the Pannonian Plain, a relatively small geographical area, but at the global scale Moina brachiata might represent a cryptic species complex with more members than currently detected.

Moina micrura was first considered as a cryptic species complex by Petrusek et al. (2004). ElíasGutiérrez et al. (2008) provided further support, but Moina macrocopa was still known to represent a well defined species. The comparison of the Mexican and the Hungarian M. macrocopa haplotypes showed deep divergence in our study. Decades passed since Goulden's (1968) work was published on the Moinidae and a thorough revision applying molecular tools is needed.

\section{Environmental factors structuring genetic variation in Moina brachiata}

Salinity and depth are important drivers of the distribution of cryptic taxa in the Moina brachiata species complex. Salinity differences are well known for their direct impact on physiology affecting species composition of zooplankton communities (Boronat et al. 2001, Frisch et al. 2006, Waterkeyn et al. 2008). Depth itself may be important in permanent waters (as a refugium against UV or visual predators), but in temporary waters it is most likely a proxy for hydroperiod, as these two variables are strongly related (Boven et al. 2008).

The abundant occurrence of the ' $\mathrm{B}$ ' individuals in the bomb craters (KNP5 and KNP8) illustrates the clearcut preference of lineage 'B' for deeper, semipermanent habitats. Our observation that cryptic taxa may be associated with differences in depth and habitat permanence is in line with other work. Schwenk et al. (2004) showed that depth associated with other factors was an important ecological variable to explain the separation of Daphnia umbra and D. longispina, later considered as Daphnia lacustris (Nilssen et al. 2007), with the former species occurring in larger and deeper waterbodies and the latter occurring in shallow ponds.

Depth is an important driver of the well-studied freshwater habitat gradient (Wellborn et al. 1996) and habitat predictability associated with depth has been repeatedly reported as an important variable explaining variation in community composition in temporary water bodies such as floodplain ponds and Mediterranean temporary wetlands (Medley \& Havel 2007, Waterkeyn et al. 2008). Our study adds to this by showing that depth is also important in structuring genetic variation across strongly related, cryptic taxa.

Several studies have provided evidence of adaptations in life history traits to hydroperiod in both cladocerans (Daphnia obtusa Kurz, 1875) (Nix \& Jenkins 2000) and copepods (Diaptomus leptopus Forbes, 1882) (Piercey \& Maly 2000). In addition, hydroperiod also selects for differences in the timing of sexual reproduction: species that are adapted to ephemeral habitats may be much more sensitive to switch to sexual reproduction when the volume of the habitat is decreasing (Roulin et al. 2013). While we picked up depth and salinity as important factors influencing the occurrence of different M. brachiata clades, part of this impact may be mediated by biotic interactions like predation, which are associated with hydroperiod (Wellborn et al. 1996).

The importance of the conservation of temporary habitats with long hydroperiod has been stressed on the grounds that invertebrate communities of the short-lived wetlands tend to be nested within assemblages found in habitats with long hydroperiod (Boven \& Brendonck 2009, Waterkeyn et al. 2008). Yet, our results indicate that for conservation purposes of temporary ponds one should not be biased towards long hydroperiod, instead the selection should cover a number of habitats that differ in hydroperiod (Heino et al. 2009, Pyke 2004), providing suitable conditions both to species occupying short lived pools and to good competitors abundant in the species rich communities of longer lived temporary waters.

Multimodel ensemble means of ten regional climate models tested for 2071-2100 (Hagemann \& Jacob 2007, Hagemann et al. 2009) predict a significant drying of the catchment area of the Danube, due to a combination of higher temperatures in summer, decreased amounts of rainfall in the summer and a significant increase in evapotranspiration throughout the year. Habitats that currently are characterised by short hydroperiod under such a scenario might develop hydroperiods that are too short even for species with special adaptations, while suitable habitats for species that are adapted to longer hydroperiod might completely disappear from the area. The future occurrence of the differently adapted Moina brachiata lineages will be affected by the combined effect of habitat loss, dispersal and range shifts.

\section{Spatial distribution}

Population genetic analyses carried out for lineage ' $\mathrm{A}$ ', the most widespread and abundant taxon in the study 
area, revealed strong population subdivision resembling genetic differentiation typically found in other cyclical parthenogens. Wright's F statistics showed no separation between regions indicating the absence of geographic structure in lineage ' $A$ ' across the Great Plain. The absence of regional structure is supported also by the haplotype network analysis in which the ' $A$ ' lineage was found in all of the three studied regions. M. brachiata 'A' likely represents a taxon adapted to highly ephemeral habitats (wheeltracks, puddles) that are small in size but relatively abundant in the field.

While lineage 'A' was widespread throughout the Great Plain, the remaining M. brachiata lineages 'B', ' $\mathrm{C}$ ' and ' $\mathrm{D}$ ' occurred at low densities and were restricted to only one of the studied regions, indicating reduced colonisation capacities or strong ecological preferences limiting their distribution.

Considering the age of the bomb craters (approx. 60 years) in the Kiskunság National Park, one possible scenario explaining the distribution of M.brachiata ' $\mathrm{B}$ ', which is adapted to longer hydroperiods, is that its high frequency in the bomb craters is the result of recent colonisation events that were followed by competition against ' $\mathrm{A}$ ' and finally population expansion. KNP3 is a shallow waterlogged area used as pasture, and grazing cattle may serve as abundant dispersal vectors (JN, personal observations) between KNP5, KNP8 and KNP3.

\section{Acknowledgements}

This research was financially supported by the Hungarian National R\&D Programme (contract No: 3B023-04), ESF EUROCORES EURODIVERSITY project BIOPOOL and the OTKA-NIH CNK 80140 grant of the Hungarian Scientific Research Fund (OTKA). KS was supported by the German Science Foundation (DFG) project SCHW $830 / 6-1$ and the Biodiversity and Climate Research Centre Frankfurt am Main (BiKF; 'LOEWE_-Landes-Offensive zur Entwicklung Wissenschaftlich-ökonomischer Exzellenz' of Hesse's Ministry of Higher Education, Research and the Arts). LDM was supported by FWO project G.0614.11 STRESSFLEA-B. We thank two anonymous referees for a thorough revision and valuable suggestions. M. Tuschek, J. Vörös, Y. Moodley, T. Erös, K. Kovács, K. Vályi, N. Flórián, Á. Molnár, R. Kiss, A. Tóth and L. Somay helped with sampling, laboratory and statistical analyses, and advice on earlier versions of the manuscript.

\section{References}

Adamowicz, S. J., Petrusek, A., Colbourne, J. K., Hebert, P. D. \& Witt, J. D., 2009: The scale of divergence: a phylogenetic appraisal of intercontinental allopatric speciation in a passively dispersed freshwater zooplankton genus. - Molecular Phylogenetics and Evolution 50: 423-436.
Adamowicz, S. J. \& Purvis, A., 2005: How many branchiopod crustacean species are there? Quantifying the components of underestimation. - Global Ecology and Biogeography 14: $455-468$.

Aladin, N.V. \& Potts, W. T. W., 1995: Osmoregulatory capacity of the Cladocera. - Journal of Comparative Physiology B 164: 671-683.

Allen, M., 2007: Measuring and modeling dispersal of adult zooplankton. - Oecologia 153: 135-143.

Balian, E. V., Lévêque, C., Segers, H. \& Martens, K., 2008: The Freshwater Animal Diversity Assessment: an overview of the results. - Hydrobiologia 595: 627-637.

Belyaeva, M. \& Taylor, D. J., 2009: Cryptic species within the Chydorus sphaericus species complex (Crustacea: Cladocera) revealed by molecular markers and sexual stage morphology. - Molecular Phylogenetics and Evolution 50: 534-546.

Bickford, D., Lohman, D. J., Sodhi, N. S., Ng, P. K. L., Meier, R., Winker, K., Ingram, K. K. \& Das, I., 2007: Cryptic species as a window on diversity and conservation. - Trends in Ecology \& Evolution 22: 148-155.

Boronat, L., Miracle, M. R. \& Armengol, X., 2001: Cladoceran assemblages in a mineralization gradient. - Hydrobiologia 442: 75-88.

Boven, L., Stoks, R., Forró, L. \& Brendonck, L., 2008: Seasonal dynamics in water quality and vegetation cover in temporary pools with variable hydroperiods in Kiskunság (Hungary). - Wetlands 28: 401-410

Boven, L. \& Brendonck, L., 2009: Impact of hydroperiod on seasonal dynamics in temporary pool cladoceran communities. - Fundamental and Applied Limnology / Archiv für Hydrobiologie 174: 147-157.

Brendonck, L., Jocque, M., Hulsmans, A. \& Vanschoenwinkel, B., 2010: Pools 'on the rocks': freshwater rock pools as model system in ecological and evolutionary research. Limnetica 29: 25-40.

Briski, E., Cristescu, M.E., Bailey, S.A. \& MacIsaac, H. J., 2011: Use of DNA barcoding to detect invertebrate invasive species from diapausing eggs. - Biological Invasions 13: 1325-1340.

Clement, M., Posada, D. \& Crandall, K. A., 2000: TCS: a computer program to estimate gene genealogies. - Molecular Ecology 9: 1657-1660.

Cristescu, M.E.A. \& Hebert, P.D. N., 2002: Phylogeny and adaptive radiation in the Onychopoda (Crustacea, Cladocera): evidence from multiple gene sequences. - Journal of Evolutionary Biology 15: 838-849.

Dudgeon, D., Arthington, A. H., Gessner, M. O., Kawabata, Z.I., Knowler, D. J., Lévêque, C., Naiman, R. J., Prieur-Richard, A.-H., Soto, D., Stiassny, M. L. J. \& Sullivan, C.A., 2006: Freshwater biodiversity: importance, threats, status and conservation challenges. - Biological Reviews 81: 163-182.

Eitam, A., Blaustein, L., Van Damme, K., Dumont, H. J. \& Martens, K., 2004: Crustacean species richness in temporary pools: relationships with habitat traits. - Hydrobiologia 525: 125-130.

Elías-Gutiérrez, M., Jerónimo, F. M., Ivanova, N. V., ValdezMoreno, M. \& Hebert, P. D. N., 2008: DNA barcodes for Cladocera and Copepoda from Mexico and Guatemala, highlights and new discoveries. - Zootaxa 1839: 1-42.

Folmer, O., Black, M., Hoeh, W., Lutz, R. \& Vrijenhoek, R., 1994: DNA primers for amplification of mitochondrial cytochrome c oxidase subunit I from diverse metazoan inver- 
tebrates. - Molecular Marine Biology and Biotechnology 3: 294-297.

Forró, L., Korovchinsky, N. M., Kotov, A.A. \& Petrusek, A., 2008: Global diversity of cladocerans (Cladocera; Crustacea) in freshwater. - Hydrobiologia 595: 177-184.

Frisch, D., Moreno-Ostos, E. \& Green, A., 2006: Species richness and distribution of copepods and cladocerans and their relation to hydroperiod and other environmental variables in Doñana, south-west Spain. - Hydrobiologia 556: 327-340.

Gama-Flores, J., Sarma, S. \& Nandini, S., 2007: Exposure time-dependent cadmium toxicity to Moina macrocopa (Cladocera): a life table demographic study. - Aquatic Ecology 41: 639-648.

Goulden, C.E., 1968: The systematics and evolution of the Moinidae. - Transactions of the American Philosophical Society 58: $1-101$.

Green, A. J., Jenkins, K. M., Bell, D., Morris, P. J. \& Kingsford, R. T., 2008: The potential role of waterbirds in dispersing invertebrates and plants in arid Australia. - Freshwater Biology 53: 380-392.

Hagemann, S. \& Jacob, D., 2007: Gradient in the climate change signal of European discharge predicted by a multimodel ensemble. - Climatic Change 81: 309-327.

Hagemann, S., Göttel, H., Jacob, D., Lorenz, P. \& Roeckner, E., 2009: Improved regional scale processes reflected in projected hydrological changes over large European catchments. - Climate Dynamics 32: 767-781.

Hall, T.A., 1999: BioEdit: a user-friendly biological sequence alignment editor and analysis program for Windows 95/98/ NT. - Nucleic Acids Symposium Series, pp. 95-98.

Havel, J. E. \& Shurin, J. B., 2004: Mechanisms, effects, and scales of dispersal in freshwater zooplankton. - Limnology and Oceanography 49: 1229-1238.

Hebert, P. D. N. \& Beaton, M. J., 1989: Methodologies for allozyme analysis using cellulose acetate electrophoresis a practical handbook. - Helena Laboratories, Beaumont, Texas, pp. 1-31.

Heino, J., Virkkala, R. \& Toivonen, H., 2009: Climate change and freshwater biodiversity: detected patterns, future trends and adaptations in northern regions. - Biological Reviews 84: $39-54$.

Huelsenbeck, J. P. \& Ronquist, F., 2001: MRBAYES: Bayesian inference of phylogenetic trees. - Bioinformatics 17: $754-755$.

Hulsmans, A., Vanschoenwinkel, B., Pyke, C., Riddoch, B. J. \& Brendonck, L., 2008: Quantifying the hydroregime of a temporary pool habitat: a modelling approach for ephemeral rock pools in SE Botswana. - Ecosystems 11: 89-100.

Jenkins, D. G., Grissom, S. \& Miller, K., 2003: Consequences of prairie wetland drainage for crustacean biodiversity and metapopulations. - Conservation Biology 17: 158-167

Jobb, G., 2008: TREEFINDER version of October 2008. Munich, Germany. - Distributed by the author at www.treefinder.de

Jongman, R. H. G., ter Braak, C. J. F. \& Van Tongeren, O. F. R., 1995: Data Analysis in Community and Landscape Ecology, Pudoc, Wageningen. - Cambridge University Press, Cambridge.

Lefébure, T., Douady, C. J., Gouy, M. \& Gibert, J., 2006: Relationship between morphological taxonomy and molecular divergence within Crustacea: Proposal of a molecular threshold to help species delimitation. - Molecular Phylogenetics and Evolution 40: 435-447.
Legendre, P. \& Anderson, M. J., 1999: Distance-based redundancy analysis: testing multispecies responses in multifactorial ecological experiments. - Ecological Monographs 69: $1-24$.

Librado, P. \& Rozas, J., 2009: DnaSP v5: A software for comprehensive analysis of DNA polymorphism data. - Bioinformatics 25: 1451-1452.

Machordom, A., Araujo, R., Erpenbeck, D. \& Ramos, M.A., 2003: Phylogeography and conservation genetics of endangered European Margaritiferidae (Bivalvia: Unionoidea). Biological Journal of the Linnean Society 78: 235-252.

Maier, G., 1992: Development, reproduction and growth pattern of two coexisting, pond dwelling cladocerans. - Internationale Revue der gesamten Hydrobiologie 77: 621- $\overline{632 .}$

Mangas-Ramírez, E., Sarma, S. S. S. \& Nandini, S., 2004: Recovery patterns of Moina macrocopa exposed previously to different concentrations of cadmium and methyl parathion: life-table demography and population growth studies. - Hydrobiologia 526: 255-265.

Medley, K. \& Havel, J., 2007: Hydrology and local environmental factors influencing zooplankton communities in floodplain ponds. - Wetlands 27: 864-872.

Miller, M. P., 1997: Tools for population genetic analyses (TFPGA) 1.3: A Windows program for the analysis of allozyme and molecular population genetic data. - Computer software distributed by author.

Naiman, R., 2008: Foreword. - Hydrobiologia 595: 1-2.

Nei, M., 1978: Estimation of average heterozygosity and genetic distance from a small number of individuals. - Genetics 89: 583-593.

Nīssen, J.P., Hobæk, A., Petrusek, A. \& Skage, M., 2007: Restoring Daphnia lacustris G. O. Sars, 1862 (Crustacea, Anomopoda): a cryptic species in the Daphnia longispina group. - Hydrobiologia 594: 5-17.

Nix, M. H. \& Jenkins, D. G., 2000: Life history comparisons of Daphnia obtusa from temporary ponds, cultured with a lowquality food. - Aquatic Ecology 34: 19-27.

Petrusek, A., Černý, M. \& Audenaert, E., 2004: Large intercontinental differentiation of Moina micrura (Crustacea: Anomopoda): one less cosmopolitan cladoceran? - Hydrobiologia 526: 73-81.

Petrusek, A., Hobæ k, A., Nilssen, J. P., Skage, M., Černy, M., Brede, N. \& Schwenk, K., 2008: A taxonomic reappraisal of the European Daphnia longispina complex (Crustacea, Cladocera, Anomopoda). - Zoologica Scripta 37: 507-519.

Petrusek, A., Thielsch, A. \& Schwenk, K., 2012: Mitochondrial sequence variation suggests extensive cryptic diversity within the Western Palaearctic Daphnia longispina complex. - Limnology and Oceanography 57: 1838-1845.

Pfenninger, M. \& Schwenk, K., 2007: Cryptic animal species are homogeneously distributed among taxa and biogeographical regions. - BMC Evolutionary Biology 7: 121.

Piercey, D. W. \& Maly, E. J., 2000: Factors influencing the induction of diapausing egg production in the calanoid copepod Diaptomus leptopus. - Aquatic Ecology 34: 9-17.

Pyke, C. R., 2004: Habitat Toss confounds climate change impacts. - Frontiers in Ecology and the Environment 2: $178-182$.

Posada, D., 2003: Using Modeltest and PAUP* to select a model of nucleotide substitution. - In: Baxevanis, A. D., Davison, D. B., Page, R. D. M., Petsko, G. A., Stein, L. D. \& Stormo, G. D. (eds): Current Protocols in Bioinformatics. John Wiley \& Sons, New York, pp. 6.5.1-6.5.14. 
Ramsar, C., 2002: Ramsar Convention on Wetlands, Resolution VIII.33 Guidance for identifying, sustainably managing, and designating temporary pools as Wetlands of International Importance. 1-7. http://www.ramsar.org/cda/en/ramsar-documents-resol-resolution-viii-33/main/ramsar/1-31$107 \% 5 \mathrm{E} 21452 \_4000 \quad 0$

R Development Core Team, 2011: R: A language and environment for statistical computing. - R Foundation for Statistical Computing, Vienna, Austria. ISBN 3-900051-07-0. Available from: http://www.R-project.org. Date visited: 11.06.2013.

Ronquist, F. \& Huelsenbeck, J. P., 2003: MrBayes 3: Bayesian phylogenetic inference under mixed models. - Bioinformatics 19: 1572-1574.

Roulin, A.C., Routtu, J., Hall, M. D., Janicke, T., Colson, I., Haag, C. R. \& Ebert, D., 2013: Local adaptation of sex induction in a facultative sexual crustacean: insights from QTL mapping and natural populations of Daphnia magna. - Molecular Ecology 22: 3567-3579.

Schwenk, K., Sand, A., Boersma, M., Brehm, M., Mader, E., Offerhaus, D. \& Spaak, P., 1998: Genetic markers, genealogies and biogeographic patterns in the cladocera. -Aquatic Ecology 32: 37-51.

Schwenk, K., Junttila, P., Rautio, M., Billiones, R., Dove, O., Bastiannsen, F. \& Streit, B., 2004: Ecological, morphological, and genetic differentiation of Daphnia (Hyalodaphnia) from the Finnish and Russian subarctic. - Limnology and Oceanography 49: 532-539.

Tamura, K., Peterson, D., Peterson, N., Stecher, G., Nei, M. \& Kumar, S., 2011: MEGA5: Molecular evolutionary genetics analysis using maximum likelihood, evolutionary distance, and maximum parsimony methods. - Molecular Biology and Evolution 28: 2731-2739.

Submitted: 15 January 2013; accepted: 20 December 2013.
Tatsuta, H., Yao, I. \& Tanaka, Y., 2009: Isolation of eight microsatellite markers from Moina macrocopa for assessing cryptic genetic structure in the wild. - Molecular Ecology Resources 9: 904-906.

Tavernini, S., 2008: Seasonal and inter-annual zooplankton dynamics in temporary pools with different hydroperiods. Limnologica - Ecology and Management of Inland Waters 38: $63-75$.

Templeton, A. R., Crandall, K.A. \& Sing, C. F., 1992: A cladistic analysis of phenotypic associations with haplotypes inferred from restriction endonuclease mapping and DNA sequence data. III. Cladogram estimation. - Genetics 132: 619-633.

Waterkeyn, A., Grillas, P., Vanschoenwinkel, B. \& Brendonck, L., 2008: Invertebrate community patterns in Mediterranean temporary wetlands along hydroperiod and salinity gradients. - Freshwater Biology 53: 1808-1822.

Waterkeyn, A., Vanschoenwinkel, B., Elsen, S., Anton-Pardo, M., Grillas, P. \& Brendonck, L., 2010: Unintentional dispersal of aquatic invertebrates via footwear and motor vehicles in a Mediterranean wetland area. - Aquatic Conservation: Marine and Freshwater Ecosystems 20: 580-587.

Weir, B. S. \& Cockerham, C. C., 1984: Estimating F-statistics. - Evolution 38: 1358-1370.

Wellborn, G.A., Skelly, D. K. \& Werner, E. E., 1996: Mechanisms creating community structure across a freshwater habitat gradient. - Annual Review of Ecology and Systematics 27: $337-363$

Williams, W.D., Boulton, A. J. \& Taffee, R. G., 1990: Salinity as a determinant of salt lake fauna: a question of scale. - Hydrobiologia 197: 257-266.

Yin, Y., Geiger, W. \& Martens, K., 1999: Effects of genotype and environment on phenotypic variability in Limnocythere inopinata (Crustacea: Ostracoda). - Hydrobiologia 400: $85-114$.

Supplementary Table 1. Complete list of the sequences obtained in this study. Ind: individual identifier. Site: code of the sampling site, KMNP: Körös-Maros National Park, KNP: Kiskunság National Park, HNP: Hortobágy National Park. HID: haplotype ID that corresponds to Figure 2 and 4. Letters in the HID indicate the lineage, numbers are the haplotype identifiers. Lineage: indication of the different lineages based on the DNA information. Mmac = Moina macrocopa. MLG: multilocus genotype of AAT, PGI, MPI, PGM, MDH for the animals analysed in parallel for nuclear and mitochondrial variability, '00' - missing data. COI and $16 \mathrm{~S}$ : GenBank accession numbers. Geographical coordinates of the sites are listed in Table 1, except for K (EOVX768614, EOVY126538) and B (EOVX139114, EOVY526829).

\begin{tabular}{ccccccc}
\hline Ind & Site & HID & Lineage & MLG & COI & 16S \\
\hline 1 & KMNP1 & A14 & A & & JN641808 & JN651422 \\
2 & & D1 & D & & & JN641809 \\
3 & KMNP2 & A15 & A & & JN641810 & JN651423 \\
4 & KMNP3 & A1 & A & & JN641811 & JN651425 \\
5 & KMNP4 & A16 & A & & JN641812 & JN651426 \\
6 & KNP1 & A5 & A & & JN641813 & JN651427 \\
7 & & A5 & A & $22,22,44,24,22$ & JN641814 & JN651428 \\
8 & & A5 & A & $22,22,44,34,22$ & JN641815 & JN651429 \\
9 & & A12 & A & $22,22,24,44,22$ & JN641816 & JN651430 \\
10 & & A12 & A & $22,22,24,44,22$ & JN641817 & JN651431 \\
11 & & A12 & A & $22,12,24,44,22$ & JN641818 & JN651432 \\
12 & & A12 & A & $22,22,44,44,22$ & JN641819 & JN651433 \\
13 & & A12 & A & $22,22,44,44,22$ & JN641820 & JN651434 \\
14 & & A11 & A & & JN641821 & JN651435 \\
15 & & A11 & $22,22,24,24,22$ & JN641822 & JN651436 \\
\hline
\end{tabular}


Supplementary Table 1. Continued.

\begin{tabular}{|c|c|c|c|c|c|c|}
\hline Ind & Site & HID & Lineage & MLG & COI & $16 S$ \\
\hline 16 & & & $\mathrm{~A}$ & $22,22,24,44,22$ & JN641823 & \\
\hline 17 & & & $\mathrm{~A}$ & & & JN651437 \\
\hline 18 & & & A & & & JN651438 \\
\hline 19 & & & A & & & JN651439 \\
\hline 20 & & & $\mathrm{~A}$ & & & JN651440 \\
\hline 21 & & & $\mathrm{~A}$ & & & JN651441 \\
\hline 22 & KNP2 & A1 & A & & JN641824 & JN651442 \\
\hline 23 & & A5 & A & & JN641825 & JN651443 \\
\hline 24 & & A12 & $\mathrm{A}$ & & JN641826 & JN651444 \\
\hline 25 & & A7 & $\mathrm{A}$ & & JN641827 & JN651445 \\
\hline 26 & & A8 & $\mathrm{A}$ & & JN641828 & JN651446 \\
\hline 27 & & & A & & & JN651447 \\
\hline 28 & & & $\mathrm{~B}$ & & & JN651448 \\
\hline 29 & KNP3 & Al & $\mathrm{A}$ & & JN641829 & JN651449 \\
\hline 30 & & A1 & $\mathrm{A}$ & & JN651421 & JN651450 \\
\hline 31 & & A13 & A & & JN641830 & JN651451 \\
\hline 32 & KNP4 & A10 & A & & JN641831 & JN651452 \\
\hline 33 & KNP5 & A1 & $\mathrm{A}$ & $22,12,24,00,22$ & JN641832 & JN651453 \\
\hline 34 & & B1 & $\mathrm{B}$ & & JN641833 & JN651454 \\
\hline 35 & & B1 & $\mathrm{B}$ & $22,22,55,11,11$ & JN641834 & JN651455 \\
\hline 36 & & B1 & $\mathrm{B}$ & $22,22,45,11,11$ & JN641835 & JN651456 \\
\hline 37 & & $\mathrm{~B} 2$ & $\mathrm{~B}$ & $22,22,55,11,11$ & JN641836 & JN651457 \\
\hline 38 & & $\mathrm{~B} 2$ & $\mathrm{~B}$ & $22,22,55,11,11$ & JN641837 & JN651458 \\
\hline 39 & & A9 & $\mathrm{A}$ & $22,12,24,00,22$ & JN641838 & JN651459 \\
\hline 40 & & & A & $22,12,24,00,22$ & JN641839 & \\
\hline 41 & & & $\mathrm{~B}$ & $22,22,55,11,11$ & JN641840 & \\
\hline 42 & & & $\mathrm{~A}$ & $22,12,44,00,22$ & JN641841 & \\
\hline 43 & & & $\mathrm{~B}$ & $22,22,55,11,11$ & & JN651460 \\
\hline 44 & & & $\mathrm{~B}$ & $22,22,55,11,11$ & & JN651461 \\
\hline 45 & & & A & $22,12,24,00,22$ & & JN651462 \\
\hline 46 & KNP6 & B2 & $\mathrm{B}$ & & JN641842 & JN651463 \\
\hline 47 & KNP7 & A1 & A & & JN641843 & JN651464 \\
\hline 48 & & A11 & $\mathrm{A}$ & & JN641844 & JN651465 \\
\hline 49 & KNP8 & A1 & A & & JN641845 & JN651466 \\
\hline 50 & & $\mathrm{~B} 2$ & $\mathrm{~B}$ & & JN641846 & JN651467 \\
\hline 51 & & B3 & $\mathrm{B}$ & & JN641847 & JN651468 \\
\hline 52 & & B3 & $\mathrm{B}$ & & JN641848 & JN651469 \\
\hline 53 & & B3 & $\mathrm{B}$ & & JN641849 & JN651470 \\
\hline 54 & & & $\mathrm{~B}$ & & & JN651471 \\
\hline 55 & & & $\mathrm{~B}$ & & & JN651472 \\
\hline 56 & & & B & & & JN651473 \\
\hline 57 & & & B & & & JN651474 \\
\hline 58 & & & B & & & JN651475 \\
\hline 59 & HNP1 & A1 & A & & JN641850 & JN651476 \\
\hline 60 & HNP2 & A1 & A & & JN641851 & JN651477 \\
\hline 61 & & A1 & A & & JN641852 & JN651478 \\
\hline 62 & HNP3 & A6 & A & & JN641853 & JN651479 \\
\hline 63 & HNP4 & $\mathrm{A} 2$ & $\mathrm{~A}$ & & JN641854 & JN651480 \\
\hline 64 & & A4 & A & & JN641855 & JN651481 \\
\hline 65 & HNP5 & A1 & A & & JN641856 & JN651482 \\
\hline 66 & & A1 & $\mathrm{A}$ & & JN641857 & JN651483 \\
\hline 67 & HNP6 & & A & & & JN651484 \\
\hline 68 & HNP7 & A1 & A & & JN641858 & JN651485 \\
\hline 69 & & A1 & A & & JN641859 & JN651486 \\
\hline 70 & & A1 & A & & JN641860 & JN651487 \\
\hline 71 & & & A & & & JN651488 \\
\hline 72 & HNP8 & $\mathrm{C} 1$ & $\mathrm{C}$ & & JN641861 & JN651489 \\
\hline 73 & & $\mathrm{C} 2$ & $\mathrm{C}$ & & JN641862 & JN651490 \\
\hline 74 & & A3 & A & & JN641863 & JN651491 \\
\hline 75 & KNP4 & & Mmac1 & & JN657688 & JN657692 \\
\hline 76 & KNP2 & & Mmac1 & & JN657691 & JN657695 \\
\hline 77 & B & & Mmac1 & & JN657690 & JN657694 \\
\hline 78 & $\mathrm{~K}$ & & Mmac2 & & JN657689 & JN657693 \\
\hline
\end{tabular}




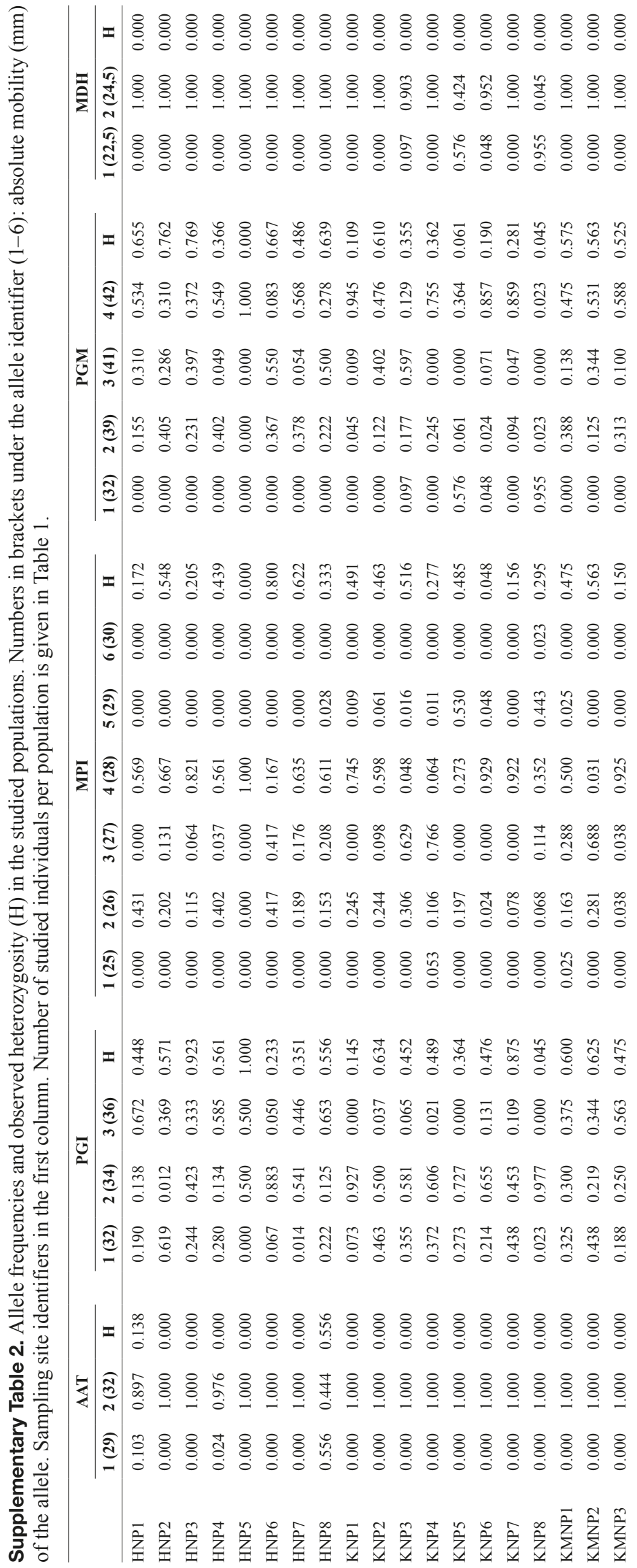




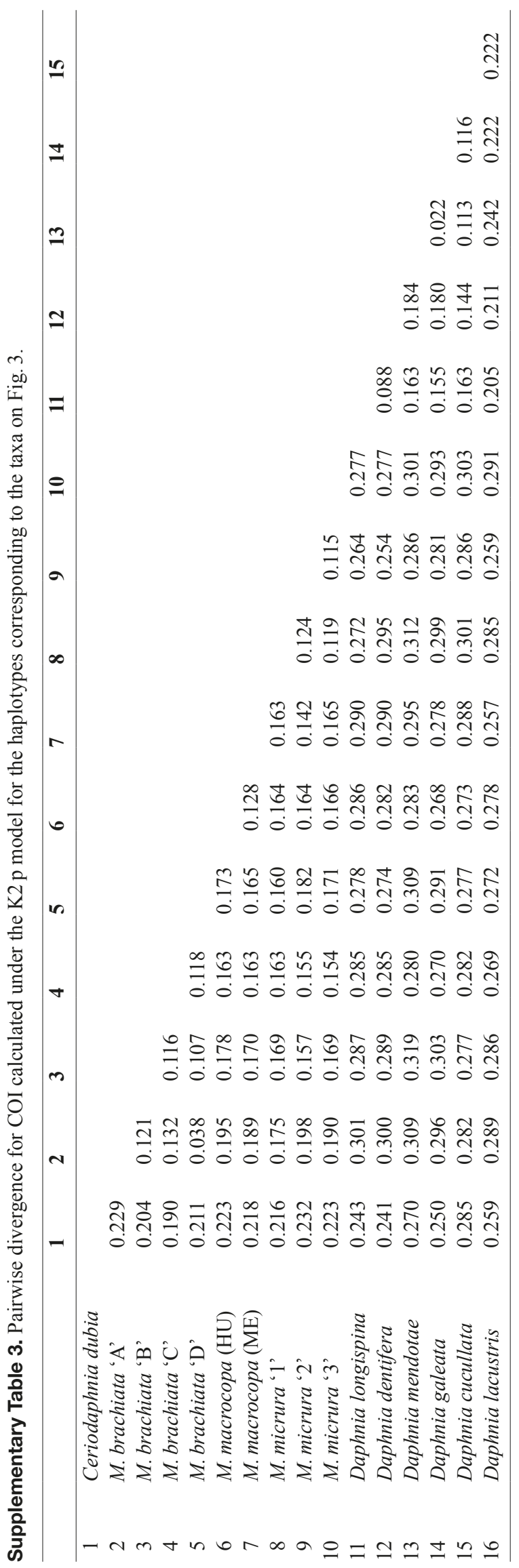

